\title{
Cocaine-induced renal infarction: report of a case and review of the literature
}

\author{
Shahrooz Bemanian*1, Mazda Motallebi ${ }^{2}$ and Saeid M Nosrati ${ }^{3}$
}

Address: ${ }^{1}$ Chief Resident, Department of Medicine, University of Southern California, Keck School of Medicine, LAC-USC Medical Center, Los Angeles, USA, ${ }^{2}$ Clinical Fellow, Department of Medicine, Division of Cardiovascular Medicine, University of Southern California, Keck School of Medicine, LAC-USC Medical Center, Los Angeles, USA and ${ }^{3}$ Associate Professor of Clinical Medicine, Department of Medicine, Division of Nephrology, University of Southern California, Keck School of Medicine, LAC-USC Medical Center, Los Angeles, USA

Email: Shahrooz Bemanian* - bemanian@usc.edu; Mazda Motallebi - mazdamot@yahoo.com; Saeid M Nosrati - nosrati@usc.edu

* Corresponding author

Published: 22 September 2005

BMC Nephrology 2005, 6:10 doi:10.1 186/147/-2369-6-10

This article is available from: http://www.biomedcentral.com/I47I-2369/6/10

This is an Open Access article distributed under the terms of the Creative Commons Attribution License (http://creativecommons.org/licenses/by/2.0), which permits unrestricted use, distribution, and reproduction in any medium, provided the original work is properly cited.

\begin{abstract}
Background: Cocaine abuse has been known to have detrimental effects on the cardiovascular system. Its toxicity has been associated with myocardial ischemia, cerebrovascular accidents and mesenteric ischemia. The pathophysiology of cocaine-related renal injury is multifactorial and involves renal hemodynamic changes, alterations in glomerular matrix synthesis, degradation and oxidative stress, and possibly induction of renal atherogenesis. Renal infarction as a result of cocaine exposure, however, is rarely reported in the literature.
\end{abstract}

Case presentation: A 48 year-old male presented with a four-day history of severe right flank pain following cocaine use. On presentation, he was tachycardic, febrile and had severe right costovertebral angle tenderness. He had significant proteinuria, leukocytosis and elevated serum creatinine and lactate dehydrogenase. Radiographic imaging studies as well as other screening tests for thromboembolic events, hypercoagulability states, collagen vascular diseases and lipid disorders were suggestive of Cocaine-Induced Renal Infarction (CIRI) by exclusion.

Conclusion: In a patient with a history of cocaine abuse presenting with fevers and flank pain suggestive of urinary tract infection or nephrolithiasis, cocaine-induced renal infarction must be considered in the differential diagnosis. In this article, we discuss the prior reported cases of CIRI and thoroughly review the literature available on this disorder. This is important for several reasons. First, it will allow us to discuss and elaborate on the mechanism of renal injury caused by cocaine. In addition, this review will demonstrate the importance of considering the diagnosis of CIRI in a patient with documented cocaine use and an atypical presentation of acute renal injury. Finally, we will emphasize the need for a consensus on optimal treatment of this disease, for which therapy is not yet standardized.

\section{Background}

Cocaine abuse has been known to have detrimental effects on the cardiovascular system. Its toxicity has been associated with myocardial ischemia, cerebrovascular accidents and mesenteric ischemia. The pathophysiology of cocaine-related renal injury is multifactorial and involves renal hemodynamic changes, alterations in glomerular matrix synthesis, degradation and oxidative 
stress, and possibly induction of renal atherogenesis. Renal infarction as a result of cocaine exposure, however, is rarely reported in the literature.

\section{Case presentation}

A 48 year-old African American male presented to our hospital with a four-day history of severe right flank pain starting several hours after smoking cocaine. His pain was associated with subjective fevers, nausea and vomiting. There was no gross hematuria or dysuria. His blood pressure was $140 / 78 \mathrm{mmHg}$, heart rate 130 beats per minute, temperature $39.5{ }^{\circ} \mathrm{C}$, respiratory rate 18 breaths per minute and his oxygen saturation was $98 \%$ on room air. Pertinent exam findings included severe right costovertebral angle tenderness, diffuse right-sided abdominal pain and a positive psoas sign on the right. Laboratory data showed a white blood cell count of $14 \times 10^{9} / \mathrm{L}(76 \%$ neutrophils), serum creatinine $1.4 \mathrm{mg} / \mathrm{dL}(124 \mu \mathrm{mol} / \mathrm{L})$, lactate dehydrogenase (LDH) $704 \mathrm{U} / \mathrm{L}$ and serum creatinine kinase (CPK) 259 U/L. A urinalysis showed 3+ proteinuria, 1 to 3 red blood cells per high power field and no white blood cells or casts. Urine toxicology confirmed the presence of cocaine. A Computerized Tomography (CT) scan with contrast revealed a sharply-demarcated heterogenous area of focal decreased enhancement in the anterior right kidney consistent with renal infarct, but pyelonephritis could not be completely ruled out (figure 1). Volume-rendered Single Photon Emission-Computed Tomography (SPECT) image of a gallium scan showed no evidence of tracer localization in the right kidney to suggest an infection. It did reveal absence of tracer localization in the upper pole of the right kidney suggesting absence of perfusion to that area (figure 2). Blood and urine cultures were negative. A trans-thoracic and a subsequent trans-esophageal echocardiogram showed no evidence of intra-cardiac thrombus or valvular vegetations. Further screening tests for hypercoagulability (factor V Leiden, prothrombin gene, protein $\mathrm{C}$ and protein $\mathrm{S}$, antithrombin III, anti-phospholipid antibody and homocysteine); collagen vascular disease (rheumatoid factor and antinuclear antibody); and lipid disorders were within normal limits. Our patient was then diagnosed with CIRI by exclusion.

\section{Discussion}

Cocaine abuse and addiction continues to be a problem that plagues the entire world. Cocaine (benzoyl methylecgonine) is available in two forms: cocaine hydrochloride and the alkaloid cocaine (freebase/crack), which is made by alkanizing the salt, followed by extraction with non-polar solvents. Both forms are well absorbed through most mucous membranes [1]. The plasma half-life is approximately 45 to 90 minutes. The elimination of cocaine is predominantly controlled by its biotransformation since its renal clearance is only $27 \mathrm{~mL} / \mathrm{min} \mathrm{[2].} \mathrm{The}$ pathways for the biotransformation involve plasma and liver cholinesterases that produce benzoyl and ethyl methylecgonine which are water-soluble metabolites excreted in urine [3].

The pathophysiologic effects of cocaine-induced renal injury involve several mechanisms. First, cocaine affects vascular reactivity and renal hemodynamics. This is thought to be due to its ability to inhibit uptake of catecholamines in the synapse, inhibit re-uptake of norepinephrine in sympathetically innervated tissues and release norepinephrine and epinephrine from the adrenal medulla $[4,5]$. There's also evidence that cocaine can directly increase calcium influx in vascular smooth muscle $[6,7]$. This effect has been documented in post-sympathectomy arteries as well as in umbilical arteries, which lack sympathetic innervation $[6,7]$. Second, cocaine has been shown to affect matrix synthesis degradation and oxidative stress in kidney [8]. Third, cocaine has been shown to accelerate renal atherogenesis $[9,10]$.

Although major toxic effects of cocaine such as myocardial ischemia, cerebrovascular accidents, mesenteric ischemia and placental infarcts have been well- documented in the literature, renal infarction as a complication of cocaine toxicity is rare. In this article, we will attempt to raise awareness of this under-reported entity by discussing its pathophysiology, clinical presentation and the current treatment modalities.

Common risk factors for renal infarction include valvular heart disease and atheroembolic events. Hypercoagulopathy, systemic vasculitis, blunt trauma, collagen vascular disorders, vascular intervention procedures and endocarditis are other less common risk factors associated with renal infarct.

Cocaine-induced renal damage is well-documented in the literature; however, renal infarction due to cocaine is not a well-known entity. Throughout our literature search, we identified seven other such reports (table 1) [11-17]. In one patient, a renal infarct was thought to be due to unilateral right renal artery thrombosis and embolization associated with intravenous cocaine injection [11]. Kramer et al. described a patient with a right renal thrombosis and infarction associated with protein $\mathrm{C}$ deficiency [12]. In another report, Antonovych et al. noted unusual renal involvement in two cocaine addicts [13]. One patient was a 26 year-old male who presented with malignant hypertension, who was found to have renal infarction. From this report, it is uncertain whether cocaineinduced malignant hypertension led to renal infarction or if cocaine-induced renal infarction presented as a case of malignant hypertension. The other patient was a 39 yearold male with recent cocaine use who had an emergent 


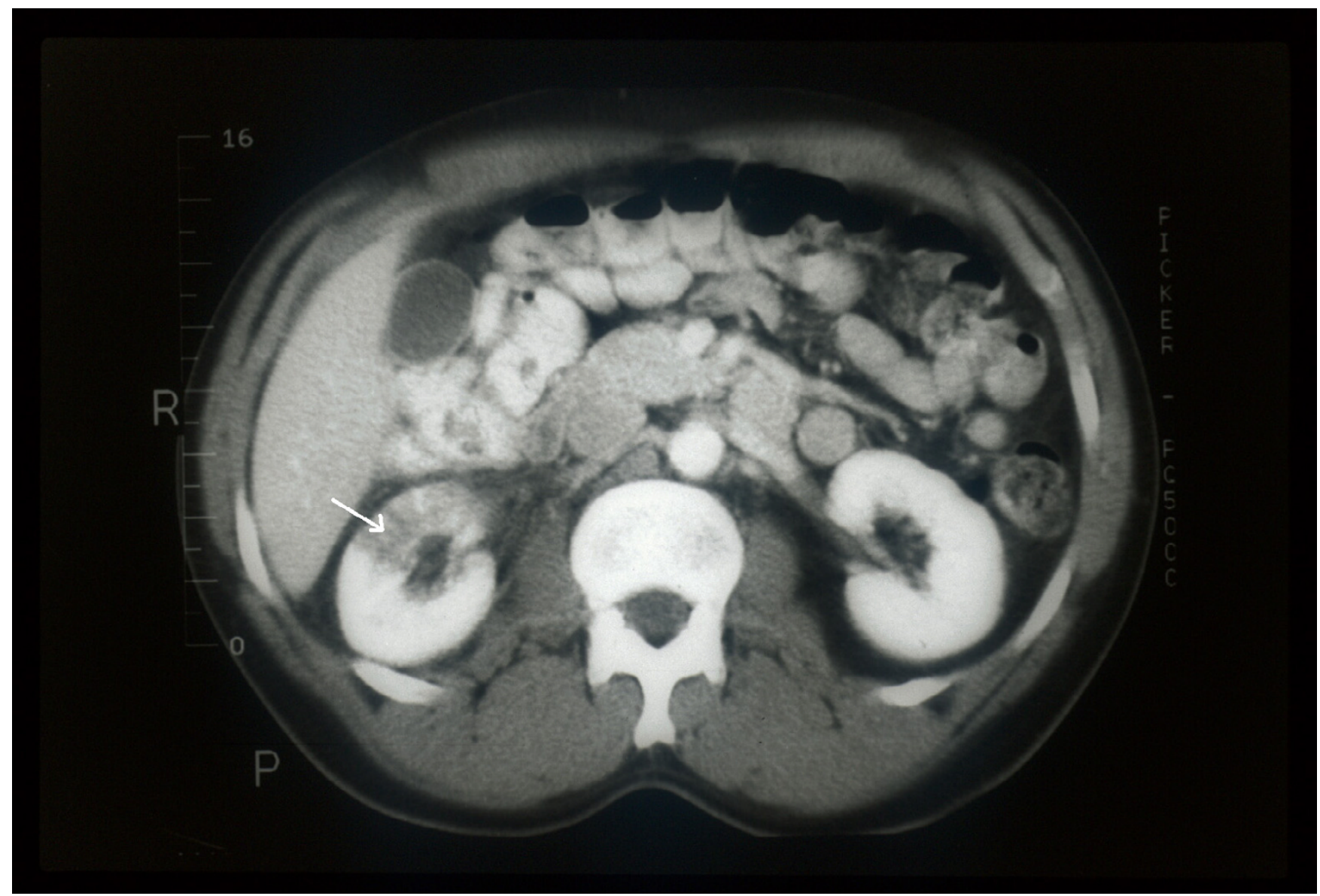

Figure I

Computerized Tomography showing areas of focal decreased enhancement of the anterior lower poles (white arrow) of the right kidney suggesting renal infarction versus pyelonephritis.

surgical nephrectomy for unclear reasons, and was found to have arterial and venous thrombosis with massive infarction. Two other cases describe right renal infarctions in patients with recent cocaine use in whom no other abnormalities were found $[14,15]$. Edmondson et al. described a 40-year-old male with renal artery dissection and thrombosis presumed to be due to cocaine which led to renal infarction [16]. Mochizuki et al. reported a 52-year-old female with recent intranasal use of cocaine who presented with acute aortic thrombosis associated with renal infarct [17].

It is not known whether there is a gender predilection for this disorder. Interestingly, all but one of the reported cases of CIRI has occurred in males. This occurrence may be due to an increased prevalence of cocaine use in males. It is also possible that males may be more genetically prone to this disorder. However, given the small number of reported cases, one cannot make any certain conclusions about genetic susceptibility.

In our review, we also noted that all but one of the reported cases of CIRI have involved the right kidney. It is generally accepted that the right renal artery is longer than the left due to its anatomical position in relation to the great vessels. Merklin et al. investigated the varied blood supply of the kidneys by dissecting 185 kidneys obtained from adult cadavers. The length of the right renal artery from the aortic origin to its division point was as long as

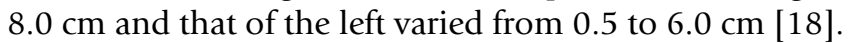
The calibers of these arteries were similar in diameter, and their average diameter was $5.5 \mathrm{~mm}$ with variations from 4 to $7 \mathrm{~mm}$ [18]. One must keep in mind that neither p-values nor confidence intervals were described in this study. 


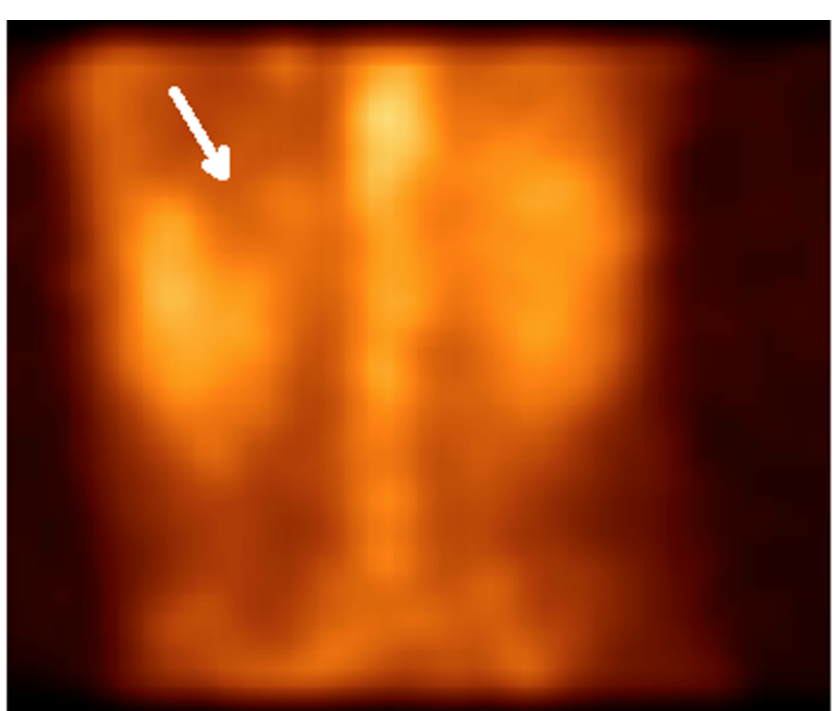

Figure 2

Volume-rendered Single Photon Emission-Computed Tomography image of a gallium scan demonstrating absence of tracer localization in the upper pole of the right kidney (white arrow) compatible with infarction.

Steady flow models for blood flow analysis in human circulation are very complex. The simplest model for blood flow through any vessel assumes a flow of a fluid with a constant viscosity through a non-tortuous and straight cylindrical tube of circular cross-section [19]. Such fluid flows are well-described by Poiseuille Equations in the honor of J. L. M. Poiseuille who performed many experiments relating pressure gradient, flow, tube geometry and length [19].

Poiseuille formulated the factors that affect flow of fluid in a tube as:

$\mathrm{Q}=\left(\mathrm{P}_{1}-\mathrm{P}_{2}\right) \pi \mathrm{r}^{4} / 8 \mathrm{~L}$

$\left(\mathrm{Q}=\right.$ flow rate; $\mathrm{P}_{1}-\mathrm{P}_{2}=$ pressure difference across a circuit; $\mathrm{r}=$ radius; $=$ viscosity of fluid; $\mathrm{L}=$ length of vessel).

Given the inverse relationship of flow to resistance:

Resistance $=$ flow $^{-1}$

We can then conclude that resistance in a vessel is directly proportional to its length, and indirectly proportional to the radius to the power of four:

Resistance $\alpha$ Length/radius 4
Since the radius of the right and left renal arteries are similar in size, we postulate that the right kidney is more prone to ischemia due to the increased resistance that it encounters by the longer length of its artery. Whether this is true or not, one must take into account the limited number of reported cases along with the lack of advanced studies to investigate the exact anatomy of the renal arteries in these particular patients.

The pathophysiology of cocaine-related renal injury is multifactorial and involves renal hemodynamic changes, alterations in glomerular matrix synthesis, degradation and oxidative stress, and possible induction of renal atherogenesis [8-10,20]. The exact mechanism of how cocaine causes renal infarction, however, is unclear, and several possibilities have been proposed. Cocaine is known to enhance platelet aggregation and increase thromboxane synthesis [21]. It is also known to inhibit synaptosomal uptake of catecholamines, block the reuptake of norepinephrine in sympathetically innervated tissues and release norepinephrine and epinephrine from the adrenal medulla $[4,5,21]$. Other vasoconstrictive factors such as endothelin have also been postulated to play a role in the vascular catastrophes caused by cocaine intoxication [22].

There is evidence that cocaine may enhance the renal cortical messenger RNA expression of tissue inhibitors of metalloproteinase-2 [8]. This would have the net effect of increasing matrix accumulation. Use of cocaine also increases the oxidative stress in the kidney. In experimental cultured kidney cells exposed to cocaine, there has been a lower level of intracellular glutathione, which is the most abundant cell thiol with antioxidant functions [23]. There is also supporting evidence that systemic atherosclerosis may be an inflammatory disorder. Both experimental and autopsy findings confirm that cocaine is an accelerator of atherogenesis $[9,10]$.

Renal infarction due to cocaine abuse usually presents with severe persistent flank and/or abdominal pain associated with nausea or vomiting with or without elevated temperature. The onset of pain is usually 2-3 hours after cocaine use, but it can be delayed for up to 4 days. All routes of cocaine administration including intravenous, insufflations, and intranasal and free-basing crack cocaine have been associated with renal infarction. Leukocytosis, microscopic hematuria and elevated levels of serum LDH are common findings. However, these findings are neither sensitive nor specific for CIRI.

Various imaging techniques including CT scan, Magnetic Resonant Imaging (MRI), angiography, Ultrasound and Nuclear Scintigraphy Scans have been used to make the diagnosis. However, MRI, angiography and nuclear scin- 
Table I: Demographic data of previously-reported cases of cocaine-induced renal infarction.

\begin{tabular}{|c|c|c|c|c|c|c|c|}
\hline Characteristics & Wohlman [II] & Antonovych [13] & Kramer [12] & Goodman [14] & Saleem [15] & $\begin{array}{l}\text { Edmondson } \\
{[16]}\end{array}$ & Mochizuki [17] \\
\hline Age (s) & 32 & 39,26 & 37 & 37 & 25 & 40 & 52 \\
\hline Sex & Male & Males & Male & Male & Male & Male & Female \\
\hline Route & IV & NR & NR & IN & IN & NR & IN \\
\hline Time of Onset & 2 hours & NR & $2-3$ hours & 2 hours & 4 days & I day & NR \\
\hline Kidney Affected & Right & $N R$ & Right & Right & Right & Right & Left \\
\hline$W B C\left(\times 10^{3} / \mu I\right)$ & 14 & NR & 23 (8\% bands) & $16(90 \% \mathrm{PMN})$ & $12.3(76 \%$ PMN $)$ & $N R$ & 19.3 \\
\hline Serum LDH (U/L) & 368 to 1860 & $N R$ & 2103 & $N R$ & 351 & $N R$ & 2100 \\
\hline Serum $\mathrm{Cr}(\mathrm{mg} / \mathrm{dL})$ & 1.2 & NR & 1.7 & 0.9 & $N R$ & 1.3 & 0.9 \\
\hline Urinanalysis & $5-10 \mathrm{RBC}$ & $N R$ & $\begin{array}{l}\text { trace protein } \\
3+\text { ketones } \\
2+\text { blood } \\
3-4 \mathrm{WBC} / \mathrm{hpf} \\
\text { I-2 RBC/hpf }\end{array}$ & $\begin{array}{l}30 \text { protein } \\
80 \text { ketones } \\
1-5 \mathrm{WBC} / \mathrm{hpf} \\
5-10 \mathrm{RBC} / \mathrm{hpf}\end{array}$ & $\begin{array}{l}2+\text { blood } \\
2 \mathrm{WBC} / \mathrm{hpf} \\
5-10 \mathrm{RBC} / \mathrm{hpf}\end{array}$ & $0 \mathrm{RBC} / \mathrm{hpf}$ & $\begin{array}{l}\text { trace protein } \\
\text { large blood } \\
3 \mathrm{WBC} / \mathrm{hpf} \\
\text { I RBC/hpf }\end{array}$ \\
\hline Treatment & $\begin{array}{l}\text { heparin \& } \\
\text { coumadin }\end{array}$ & nephrectomy & $\begin{array}{l}\text { urokinase, } \\
\text { heparin \& } \\
\text { coumadin }\end{array}$ & none & aspirin & $\begin{array}{l}\text { heparin \& } \\
\text { coumadin }\end{array}$ & $\begin{array}{l}\text { heparin, } \\
\text { antibiotics \& } \\
\text { coumadin }\end{array}$ \\
\hline $\begin{array}{l}\text { Co-existing } \\
\text { Conditions }\end{array}$ & $N R$ & NR & $\begin{array}{l}\text { DM, Protein C } \\
\text { deficiency }\end{array}$ & NR & NR & $\begin{array}{l}\text { Renal artery } \\
\text { dissection }\end{array}$ & $\begin{array}{l}\text { Aortic } \\
\text { thrombosis }\end{array}$ \\
\hline
\end{tabular}

WBC (White Blood Cell; cells $\times 10^{3} / \mathrm{ul}=$ cells $\left.\times 10^{9} / \mathrm{ul}\right) ; \mathrm{RBC}$ (Red Blood Cell); hpf (High Power Field); LDH (Lactate Dehydrogenase); PMN (Polymorphonuclear Cells); N/R (Not Reported); IV (Intravenous); IN (Intra-nasal); DM (Diabetes Mellitus); Serum Cr (Serum Creatinine; I mg/dL $=88.4 \mathrm{umol} / \mathrm{L}$ )

tigraphy are expensive, system-specific and time-consuming, and they may not be readily available at all institutions. Ultrasound lacks sensitivity and specificity for renal infarction. Therefore, CT scan has been recommended for the diagnosis of this challenging disease. CT scan, however, becomes less reliable when the infarct is global and there is loss of viable cortical rim, or when the infarct simulates a tumefactive process.

There is no consensus on the treatment of renal infarction due to cocaine use. Prior treatment modalities in the literature range from no treatment to anticoagulation, thrombolytic use, aspirin therapy and surgical nephrectomy. Given that no evidence of underlying coagulopathy or thromboembolic events were identified in our patient, we opted to conservatively manage him with supportive therapy and pain management. He was successfully discharged on hospital day six with a serum creatinine of 1.2 $\mathrm{mg} / \mathrm{dL}$ (106.1 umol/L).

\section{Conclusion}

Cocaine intoxication is associated with multiple cases of vascular injury. Renal infarction as a result of cocaine use, however, is uncommon. In a patient with a history of cocaine abuse presenting with fevers and flank pain suggestive of urinary tract infection or nephrolithiasis, cocaine-induced renal infarction must be considered in the differential diagnosis. The vasoconstrictive and thrombotic effects of cocaine are most likely the dominant factors in cocaine-induced renal infarction. The possible atherogenic effect of cocaine and the relationship of this effect to renal infarct is likely to be a long term, rather than an acute factor. The diagnosis of CIRI is based on exclusion of other entities that cause renal infarct (e.g. hypercoagulable states due to factor deficiency, autoimmune diseases and thromboembolic events), in conjunction with documented cocaine use and appropriate radiographic studies. We highly recommend non-invasive evaluation of the renal arterial supply in patients with CIRI in order to broaden our knowledge of this disorder, and conceivably better understand its selectivity for one kidney. Thus far, there is no agreement on the management of patients with this disease. In fact, it is difficult to suggest a uniform therapeutic approach to this disorder because one cannot predict whether the infarct will be due to vasospasm, thrombosis or both. In addition, the extent of the renal infarct will likely influence clinical management and outcome. Although anticoagulation, antithrombotic, conservative managements as well as surgical approaches have been attempted with variable success, perhaps the most plausible treatment would be to prevent this misfortune by patient education.

\section{Competing interests}

The author(s) declare that they have no competing interests.

\section{Authors' contributions}

SB performed the main background search and drafted the manuscript. MM participated in the study design and 
helped to draft the manuscript. SMN participated in the study design and coordination and helped to draft the manuscript. All authors read and approved the final manuscript.

\section{Acknowledgements}

The Authors would like to thank Dr. Arash D. Tehranzadeh for his interpretation of the radiological images. Written consent was obtained from the patient for publication of the study.

\section{References}

I. Pitts WR, Lange RA, Cigarroa JE, Hillis DL: Cocaine-induced myocardial ischemia and infarction: Pathophysiology, recognition and management. Prog Cardiovasc Dis 1997, 40:65-76.

2. Inaba T: Cocaine: Pharmacokinetics and biotransformation in man. Can J Physiol Pharmacol 1989, 67: I I54-II 57.

3. Chow MJ, Amdre JJ, Ruo TI, Atkinson AJ, Bowsher DJ, Pischman MW: Kinetics of cocaine distribution, elimination and chronotropic effects. Clin Pharmacol Ther 1985, 38:3 I8-324.

4. Chiueh CC, Kopin IJ: Centrally mediated release by cocaine of endogenous epinephrine and norepinephrine from the sympathoadrenal medullary system of unanesthetized rats. J Pharmacol Exp Ther 1978, 205:148-154.

5. Karch SB: Serum catecholamines in cocaine-intoxicated patients with cardiac symptoms. Ann Emerg Med 1987, 16:48I-482.

6. Rogione AJ, Steg PG, Gal D, Isner JM: Cocaine causes endothelium-independent vasoconstriction of vascular smooth muscle [abstract]. Circulation 1988, 78:5436A.

7. Isner J, Chokshi SK: Cardiovascular complications of cocaine. Curr Probl Cardiol 1991, 16:89-123.

8. Kapasi AJ, Mattana J, Wagner J: Morphine amplifies cocaineinduced renal cortical expression of tissue inhibitors of metalloproteinase (TIMP)-2 [abstract]. J Am Soc Nephrol 1997, 6:528A.

9. Kolodgie FD, Wilson PS, Corhill JF, Herderick EE, Mergner WJ, Virman R: Increased prevalence of aortic fatty streaks in cholesterol-fed rabbits administered intravenous cocaine: The role of vascular endothelium. Toxicol Pathol 1993, 21:425-434.

10. Dressler FA, Malekzadeh S], Roberts WC: Quantitative analysis of amounts of coronary artery narrowing in cocaine addicts. Am J Cardiol 1990, 65:303-308.

II. Wohlman RA: Renal artery thrombosis and embolization associated with intravenous cocaine injection. South Med J 1987, 80:928-930.

12. Kramer RK, Turner RC: Renal infarction associated with cocaine use and latent protein c deficiency. South Med J 1993, 86: $1436-1438$

13. Antonovych TT, Sabnis SG, Finkelstein A, Yadla RK: Unusual renal involvement in two cocaine addicts [abstract]. J Am Soc Nephrol 1990, I:326A.

14. Goodman PE, Rennie WP: Renal infarction secondary to nasal insufflation of cocaine. Am J Emerg Med 1995, I 3:42I-423.

15. Saleem TM, Singh M, Murtaza M, Singh A, Kasubhai M, Gnanasekaran I: Renal infarction: a rare complication of cocaine abuse. Am J Emerg Med 200I, 19:528-529.

16. Edmondson DA, Towne JB, Foley DW, Abu-Hajir M, Kochar MS: Cocaine-induced renal artery dissection and thrombosis leading to renal infarction. WM/ 2004, I03(7):66-69.

17. Mochizuki Y, Zhang M, Golestaneh L, Thananart S, Coco M: Acute aortic thrombosis and renal infarction in acute cocaine intoxication: a case report and review of literature. Clin Nephrol 2003, 60(2): 130-I33.

18. Merklin RJ, Michels NA: The variant renal and suprarenal blood supply with data on the interior phrenic, ureteral and gonadal arteries: a statistical analysis based on 185 dissections and a review of the literature. J Int Coll Surg 1958, 29:4I-76.

19. Ross J Jr: Dynamics of the Peripheral Circulation. In Best and Taylor's Physiological Basis of Medical Practice 12th edition. Edited by: West JB. Maryland: Williams \& Wilkins; 1990:138-158.
20. Nzerue CM, Hewan-Lowe K, Riley LJ Jr: Cocaine and the kidney: a synthesis of pathophysiologic and clinical perspectives. Am J Kidney Dis 2000, 35:783-785.

21. Lange RA, Hills LD: Cardiovascular complications of cocaine use. N Eng J Med 200I, 345:35I-358.

22. Kohan DE: Endothelins in normal and diseased kidney. Am J Kidney Dis 1997, 29:2-25.

23. Palamara AT, Difrancesco P, Ciriolo MR, Bue C, Lafaria E, Rotilo G, Garaci E: Cocaine increases Sendai virus replication in cultured epithelial cells: Critical role of intracellular redox status. Biochem Biophys Res Commun 1996, 228:579-585.

\section{Pre-publication history}

The pre-publication history for this paper can be accessed here:

http://www.biomedcentral.com/1471-2369/6/10/prepub
Publish with Biomed Central and every scientist can read your work free of charge

"BioMed Central will be the most significant development for disseminating the results of biomedical research in our lifetime. " Sir Paul Nurse, Cancer Research UK

Your research papers will be:

- available free of charge to the entire biomedical community

- peer reviewed and published immediately upon acceptance

- cited in PubMed and archived on PubMed Central

- yours - you keep the copyright

Submit your manuscript here:

http://www.biomedcentral.com/info/publishing_adv.asp
BiolMedcentral 